\title{
EFFECT OF AGE, AND SPLEEN AND TREATMENT STATUS ON MALE REPRODUCTIVE HORMONES AND SOME PHYSIOLOGICAL PARAMETER LEVELS IN PATIENTS WITH BETA-THALASSEMIA MAJOR
}

\author{
JAMELA JOUDA ${ }^{1 *}$, RAJWAN ABDULJABBAR GHAZZAY², WAFAA F AL-MOSAWY3 \\ ${ }^{1}$ Department of Biology, College of Science, Mustansiriyah University, Baghdad, Iraq. ${ }^{2}$ Department of Pharmaceutical Chemistry, College of \\ Pharmacy, Kerbala University, Kerbala, Iraq. ${ }^{3}$ Department of Pharmacology, College of Pharmacy, Kerbela University, Kerbala, Iraq. \\ Email: jamela.jouda@uomustansiriyah.idu.iq \\ Received: 17 January 2019, Revised and Accepted: 08 April 2019
}

\section{ABSTRACT}

Objective: This research was conducted to study the relationship between spleen status and chelation treatment status with the male reproductive hormones and some physiological parameter levels.

Methods: A total of 35 males with thalassemia major (TM) patients are recruited. Patients are grouped according to (1) their age into two groups; $<18$ years and $\geq 18$ years, (2) their spleen status into two groups; splenectomize and non-splenectomize, and (3) their chelation treatment status into two groups; regulation and irregulation. Body mass index (BMI) was calculated and blood was collected from all patients just before blood transfusion session. $\mathrm{Hb}, \mathrm{ABO}$ blood groups, ferritin, and hormone (luteinizing hormone [LH], follicle-stimulating hormone [FSH], testosterone, prolactin, and cortisone) levels were determined.

Results: The highest frequency of thalassemia was in Group 0 and the lowest was in AB. BMI was higher in TM patients aged $\geq 18$ years, TM patients with splenectomize, and TM patient who take the treatment irregularly. TM patients aged $\geq 18$ years have high level of LH, FSH, and testosterone. TM patients without splenectomize have higher FSH, prolactin, and testosterone. TM patients take the treatment regularly have significantly higher testosterone levels and non-significantly lower FSH level.

Conclusion: The levels of cortisol and prolactin hormones are not disturbed in TM patients and not associated with the rate of transfusion, but the level of $\mathrm{Hb}$ and ferritin leads to underweight in BMI and may lead to endocrine dysfunction, especially sexual hormones (FSH, LH, and testosterone). These BMI and sex hormones are related to age, spleen, and treatment status.

Keywords: Thalassemia major patients, Luteinizing hormone, Follicle-stimulating hormone, Testosterone, Chelation therapy, Splenectomy.

(c) 2019 The Authors. Published by Innovare Academic Sciences Pvt Ltd. This is an open access article under the CC BY license (http://creativecommons. org/licenses/by/4. 0/) DOI: http://dx.doi.org/10.22159/ajpcr.2019.v12i5.30728

\section{INTRODUCTION}

$\beta$-Thalassemia is a serious genetic disorder that leads to a significant increase in both morbidity and acute and chronic mortality, especially in our developing countries, for at least the next few decades $[1,2]$. In the past, children with the disease rarely succeed to survival after adolescence [3]. In the late 1970s, quality of the patient's life was improved due to introduction of optimal red blood cell transfusions [4], but severe endocrine complications are developed in patients with multitransfused due to iron overload [5]. The main reason for iron overload is increased iron absorption in the intestine due to it's requested by the body to produce new erythrocytes rather than the inefficient [6] or due to transfusions sometimes [7]. Iron overload caused many complications. One of these complications is hypogonadism in thalassemia patients $[8,9]$.

Other complication of $\beta$-thalassemia includes hyperactivity of spleen (hypersplenism) which leads to splenomegaly. Splenomegaly is characterized by an increase in mechanical filtration of spleen and early destruction of blood components [10].

Splenectomy and almost daily subcutaneous chelation are the main therapies to reduce hemolysis resulting increase the lifespan of red cell, eliminate the need for regular transfusions, prevent the risk of iron overload [11], and normalize reproductive and sexual life [12].

Although thousands of people over the world have $\beta$-thalassemia and suffer from problems in the reproductive health, literature on these issues is rare, especially the relationship between the type of treatment and the sexual health. Hence, this research aimed to study the relationship between spleen status (splenectomize or not) and chelation treatment status (regulation or irregulation) with the male reproductive hormones (luteinizing hormone [LH], follicle-stimulating hormone $[\mathrm{FSH}]$, and testosterone) and some physiological parameter levels.

\section{METHODS}

A total of 35 Iraqi male with beta-thalassemia major (TM) patients are recruited from thalassemia center/Children's Teaching Hospital, Kerbala/Iraq, at the age of 14-29 years. All patients are blood transfusion dependent (20 ml packed RBCs/kg, at 2-3 weeks interval) to maintain a pretransfusion hemoglobin concentration above $8 \mathrm{~g} / \mathrm{l}$; also, all of them were on iron chelation therapy. A written informed patient consent was taken from all the volunteers in the study. The age, blood groups, spleen status, and treatment status are recorded from the profile of all patients. Patients are grouped according to:

1. Their age into two groups; $<18$ years and $\geq 18$ years

2. Their spleen status into two groups; splenectomize and nonsplenectomize

3. Their chelation treatment status into two groups; regulation and irregulation.

The body weights, by body balance, and height, by paper tape, of patients were measured and the body mass index (BMI) was calculated as weight in kilograms divided by height in meters squared [13]. 
At morning and after taking consent, $5 \mathrm{ml}$ blood was collected from all patients 2-3 weeks after the previous transfusion. Hb level was determined by gemmy hematocrit. Then, the rest of blood was collected in a dry sterilized test tube. The blood samples were centrifuged for $5 \mathrm{~min}$ at $3000 \mathrm{rpm}$ to obtain the serum that used to determine:

1. Male reproductive hormones

a. FSH and LH levels by two-site immune enzymometric assay using the ST AIA-PACK FSH or LH, which is performed entirely in the AIA-PACK.

b. Testosterone levels by competitive immunoenzymometric assay the ST AIA-PACK testosterone, which is performed entirely in the AIA-PACK.

2. Some physiological parameters

a. Ferritin level by an enzyme-linked assay method using a kit supplied by Biomerieux (France), measured automatically with Minividas, Biomerieux (France).

b. Cortisol level according to Tosoh Company.

c. Prolactin by two-site immune enzymometric assay using the ST AIA-PACK PRL, which is performed entirely in the AIA-PACK.

Results are expressed as mean \pm standard error or percentage. Data were analyzed by one sample test for percentages and by Student's t-test for other parameters comparison using Statview version 5.0. Differences were considered significant when $\mathrm{p}<0.05$.

\section{RESULTS}

Table 1 showed the basic clinical manifestations of TM patients, in which there were only significant differences between the frequencies of blood groups, the highest frequency was Group 0 and the lowest was AB. The rest parameters showed non-significant differences.

Table 1: The basic clinical manifestations of TM patients

\begin{tabular}{lll}
\hline Character & Sample value & p value \\
\hline Age & & \\
$\quad$ Range & $15-30$ & \\
Mean \pm SD & $20.15 \pm 4.17$ & 0.126 \\
$<18$ years n (\%) & $14(40)$ & \\
$\geq 18$ years n (\%) & $21(60)$ & 0.043 \\
Blood groups n (\%) & $9(26)$ & \\
A & $9(26)$ & \\
B & $3(6)$ & \\
AB & $14(42)$ & \\
O & & \\
Spleen status n (\%) & $21(60)$ & \\
Splenectomize & $14(40)$ & \\
Non-splenectomize & $14(40)$ & \\
Treatment status n $(\%)$ & $21(60)$ & \\
Regular & & \\
Irregular & & \\
\hline SD: Standard deviation & & \\
& &
\end{tabular}

The result of estimated parameters in all groups is showed in Table 2; it showed that TM patients aged $<18$ years have significant higher $\mathrm{Hb}$ value than those who aged $\geq 18$ years while TM patients aged $\geq 18$ years have significant higher BMI value. However, ferritin showed nonsignificant difference between the two groups of TM patients.

According to spleen status, TM patients with splenectomize have significant higher BMI value than those with non-splenectomize, while the rest parameters showed non-significant differences.

Finally, according to chelation treatment status, TM patients who take the treatment irregularly have significant higher BMI and ferritin values compared to who take the treatment regularly. However, the rest parameters showed non-significant differences.

Table 3 showed the results of hormones in all groups, in which TM patients aged $\geq 18$ years have high level of LH, FSH, and testosterone compared to patient aged $<18$ years, but only the difference in LH and testosterone levels reached the significant.

TM patients without splenectomize have higher FSH, prolactin, and testosterone compared to patients with splenectomize, but only FSH and prolactin reached the significant.

TM patients take the treatment regularly have significantly higher testosterone levels and non-significantly lower FSH level compared to who take treatment irregularly.

\section{DISCUSSION}

Thalassemia was described as a severe anemia type which associated with splenomegaly and changes of bone marrow in children by Cooley and Lee [14]. Blood transfusion is the available treatment of these patients [15], but with the time, it leads to many complications [16] such as iron overload accumulated in visceral organs such as heart, liver, and endocrine glands [17]. Chelation treatment can decrease iron level in these patients. Splenomegaly can also occur in the thalassemia patients due to the increase rate of RBC removal by the spleen [18]; the available treatment, in this case, is splenectomy [19].

Mohssin et al. showed that the frequency of thalassemia in O blood group is very high, but in AB blood group is very low in Bagdad/Iraq [20]. The same results were reported by Mohammad et al. in Iran [21] and in our previous research [22], while Saha and Sahadalal [23] and Iqbal et al. [24] found that the frequency of thalassemia in B blood group was higher compared to other blood groups. In this work, the highest frequency of thalassemia in $\mathrm{O}$ blood group and the lowest in $\mathrm{AB}$ were detected.

Many studies reported that children with TM suffer from many complications which including growth retardation, impaired immune function, and low BMI [25-27]. It is well established that the BMI was influenced by many parameters including age, gender, endocrine

Table 2: Estimation of parameter's level in both groups of TM patients according to age, and spleen and treatment status

\begin{tabular}{|c|c|c|c|}
\hline Characters & $\mathrm{Hb}(\mathrm{g} / \mathrm{dl})$ & BMI $\left(\mathrm{kg} / \mathrm{m}^{2}\right)$ & Ferritin (ng/ml) \\
\hline \multicolumn{4}{|l|}{ Age } \\
\hline$<18$ years & $9.3 \pm 0.3^{*}$ & $17.7 \pm 0.5$ & $2788.2 \pm 421.4$ \\
\hline$\geq 18$ years & $8.6 \pm 0.2$ & $19.5 \pm 0.5^{*}$ & $3265.9 \pm 442.03$ \\
\hline $\mathrm{p}$ value & 0.045 & 0.031 & 0.51 \\
\hline \multicolumn{4}{|l|}{ Spleen status } \\
\hline Splenectomize & $8.97 \pm 0.24$ & $19.8 \pm 0.43^{*}$ & $3125.0 \pm 493.8$ \\
\hline Non-splenectomize & $8.81 \pm 0.23$ & $17.96 \pm 0.64$ & $3427.0 \pm 466.3$ \\
\hline \multicolumn{4}{|l|}{ Treatment status } \\
\hline Regular & $8.87 \pm 0.31$ & $17.9 \pm 0.64$ & $2002.3 \pm 394.9$ \\
\hline Irregular & $8.95 \pm 0.21$ & $19.96 \pm 0.44^{*}$ & $3604.7 \pm 436.3^{*}$ \\
\hline $\mathrm{p}$ value & 0.840 & 0.0245 & 0.0238 \\
\hline
\end{tabular}

*Significant differences between two groups 
Table 3: Hormones levels in the TM patients according to age, spleen, and treatment status

\begin{tabular}{|c|c|c|c|c|c|}
\hline Characters & LH & FSH & Prolactin & Testosterone & Cortisol \\
\hline \multicolumn{6}{|l|}{ Age } \\
\hline$<18$ years & $1.81 \pm 0.5$ & $3.53 \pm 0.79$ & $9.83 \pm 0.11$ & $2.63 \pm 0.14$ & $9.55 \pm 0.79$ \\
\hline$\geq 18$ years & $4.57 \pm 0.73^{*}$ & $5.75 \pm 1.11$ & $8.95 \pm 0.68$ & $8.02 \pm 1.86^{*}$ & $10.31 \pm 1.09$ \\
\hline $\mathrm{p}$ value & 0.03 & 0.34 & 0.48 & 0.04 & 0.60 \\
\hline \multicolumn{6}{|l|}{ Spleen status } \\
\hline Splenectomize & $3.53 \pm 0.74$ & $3.75 \pm 0.72$ & $8.04 \pm 0.57$ & $4.86 \pm 1.59$ & $10.52 \pm 1.47$ \\
\hline Non-splenectomize & $4.23 \pm 0.77$ & $8.02 \pm 1.70^{*}$ & $11.09 \pm 1.01 *$ & $7.16 \pm 1.86$ & $9.59 \pm 0.65$ \\
\hline \multicolumn{6}{|l|}{ Treatment status } \\
\hline Regular & $4.36 \pm 1.04$ & $3.17 \pm 0.53$ & $9.55 \pm 1.04$ & $8.71 \pm 2.62 *$ & $10.9 \pm 0.45$ \\
\hline Irregular & $3.65 \pm 0.65$ & $5.93 \pm 1.25$ & $9.04 \pm 0.70$ & $3.09 \pm 0.89$ & $10.3 \pm 0.90$ \\
\hline $\mathrm{p}$ value & 0.55 & 0.15 & 0.68 & 0.029 & 0.56 \\
\hline
\end{tabular}

*Significant differences between two groups

system status, and nutrition [28]. Fung et al. [29] reported that the underweight status increased among childhood and adolescence with thalassemia. The reasons can be the presence of hypogonadism, undernutrition [30-32], and the side effects of chelation treatment, which used to decrease iron level in these patients [33]. In our results, BMI was higher in TM patients aged $\geq 18$ years, in TM patient who takes the chelation treatment irregularly, and TM patients with splenectomize compared to TM patients aged $<18$ years, TM patients who take the chelation treatment regularly, and TM patients with non-splenectomize, respectively. TM patients who take the treatment irregularly have also significant higher ferritin values compared to who take the treatment regularly.

In the classic knowledge, iron accumulated in the pituitary gland of thalassemia patients results a cytotoxic effect. These cytotoxic effects result to hyporesponsiveness of pituitary gland to GnRH and lead to hypergonadotrophic hypogonadism [34], which can appear as low estradiol or testosterone with LH and low FSH [8]. Iron overload is also exist in reproductive glands which lead to undifferentiate the sperm tubes, decrease number of Leydig cells, and interstitial fibrosis in varying degrees $[35,36]$. It is clear that during childhood, the levels of testosterone, LH, and FSH remain very low until the onset of puberty [8]. These evidences can explain the high level of LH, FSH, and testosterone in TM patients aged $\geq 18$ years compared to TM patients aged $<18$ years.

Glandular insufficiency does not respond to late chelation treatment of the disease [37], but prepuberty chelation therapy has helped patients get natural sexual maturity in some studies [8]. In contrast, another study reported that there was no difference in the frequency of pluripotent maturity when treatment began with iron ingestion at the age of 10 or earlier [18]. However, with modern drugs, iron deficiency glands may be reversible with iron intensive chelation systems [8]. In our results, TM patients take the chelation treatment regularly have significantly higher testosterone levels and non-significantly lower FSH level compared to who take treatment irregularly.

The hypothalamic-pituitary-gonadal axis is strongly involved in regulating the immune system. There is a link between the gonads and the spleen. Han et al.[38] reported that the deprivation of testosterone by surgical castration increases GnRH and many immune cytokine expressions in the spleen. Immune castration increases the production of GnRH in the spleen by eliminating the effects of the inhibitory reactions of testosterone, thereby improving the immune markers of the immune cytokines of the spleen and serum [38-40]. This can explain the high level of testosterone and prolactin in splenectomize thalassemic patients in this study.

It seems that hyperprolactinemia does not participate in the cause of hypergonadotrophic hypogonadism in thalassemia patients [30]. Plasma levels of prolactin were within the normal range of all male and female hypogonadal patients [32]. In this study, there were no differences in the prolactin levels according to age and treatment status.
The usual tests of adrenal function in patients with thalassemia have shown little weakness in function but have always worked at maximum rate to produce normal levels of cortisol spread [33]. Landon et al. [41] showed a very large suppression of function in the physiological range with a normal function reserve using the more gradual physiological cortical stimulation test [34]. This could explain why there were no differences in thalamic patients according to age, and treatment and spleen status.

\section{CONCLUSION}

The levels of cortisol and prolactin hormones are not disturbed in TM patients and not associated with the rate of transfusion, but the level of $\mathrm{Hb}$ and ferritin leads to underweight in BMI and may lead to endocrine dysfunction, especially sexual hormones (FSH, LH, and testosterone). These BMI and sex hormones are related to age, and spleen and treatment status.

\section{AUTHORS' CONTRIBUTIONS}

All authors contributed to the design and implementation of the research, to the analysis of the results, and to the writing of the manuscript.

\section{CONFLICTS OF INTEREST}

There are no conflicts of interest of any sort.

\section{REFERENCES}

1. Wangruangsathit S, Hathirat P, Chuansumrit A, Pakakasama S, Hongeng S. The correlation of transferrin saturation and ferritin in non-splenectomized thalassemic children. J Med Assoc Thai 1999;82 Suppl 1:S74-6.

2. Olivieri NF. The beta-thalassemias. N Engl J Med 1999;341:99-109.

3. Politis C, Di Palma A, Fisfis M, Giasanti A, Richardson SC, Vullo C, et al. Social integration of the older thalassaemic patient. Arch Dis Child 1990;65:984-6.

4. Sparrow RL. Time to revisit red blood cell additive solutions and storage conditions: A role for "omics" analyses. Blood Transfus 2012;10 Suppl 2:s7-11

5. Toumba M, Sergis A, Kanaris C, Skordis N. Endocrine complications in patients with thalassaemia major. Pediatr Endocrinol Rev 2007;5:642-8.

6. Collins JF, Prohaska JR, Knutson MD. Metabolic crossroads of iron and copper. Nutr Rev 2010;68:133-47.

7. Mishra AK, Tiwari A. Iron overload in beta thalassaemia major and intermedia patients. Maedica (Buchar) 2013;8:328-32.

8. Srisukh S, Ongphiphadhanakul B, Bunnag P. Hypogonadism in thalassemia major patients. J Clin Transl Endocrinol 2016;5:42-5.

9. Clarke GM, Higgins TN. Laboratory investigation of hemoglobinopathies and thalassemias: Review and update. Clin Chem 2000;46:1284-90.

10. Cao A, Galanello R. Beta-thalassemia. Genet Med 2010;12:61-76.

11. Vasilescu C, Stanciulea O, Tudor S, Stanescu D, Colita A, Stoia R, et al. Laparoscopic subtotal splenectomy in hereditary spherocytosis. To preserve the upper or the lower pole of the spleen? Surg Endosc $2006 ; 20 \cdot 748-52$. 
12. Rodgers GP. Pharmacological therapy. Baillieres Clin Haematol 1998;11:239-55.

13. World Health Organization. Appropriate Body-Mass Index for Asian Populations and its Implications for Policy and Intervention Strategies. Report of a Who Expert Consultation. In: 363. Geneva: World Health Organization; 2004.

14. Cooley TB, Lee P. A series of cases of splenomegaly in children with anemia and peculiar bone changes. Trans Am Pediatr Soc 1925;37:29-30.

15. Weatherall DJ. Disorders of globin synthesis: Thalassemia. In: Lichtman MA, Beutler E, Kipps TJ, Seligson U, Kaushansky K, Prchal JT, editors. Williams Hematology. New York: McGrawHill; 2006.

16. Borgna-Pignatti C, Galanello R. Thalassemias and related disorders. Quantitative disorders of hemoglobin synthesis. In: Greer JP, Rodgers GM, Paraskevas F, Foerster J, Lukens JN, Glader B, editors. Wintrob's Clinical Hematology. Philadelphia, PA: Lippincott Williams and Wilkins; 2004

17. Abdulzahra MS, Al-Hakeim HK, Ridha MM. Study of the effect of iron overload on the function of endocrine glands in male thalassemia patients. Asian J Transfus Sci 2011;5:127-31.

18. Ammar SA, Elsayh KI, Zahran AM, Embaby M. Splenectomy for patients with $\beta$-thalassemia major: Long-term outcomes. Egypt J Surg 2014;33:232-6.

19. Muncie HL Jr., Campbell J. Alpha and beta thalassemia. Am Fam Physician 2009;80:339-44

20. Mohssin MY, Mahmood AE, Kamal SB, Batah EH. Frequency distribution of hemoglobin variant and abo blood groups among thalassemia patients from ibn-al-baladi pediatric hospital in Baghdad/ Iraq. World J Pharm Pharm Sci 2015;4:31-9.

21. Mohammad AF, Pourfathollah A. Association of abo and rh blood groups to blood borne infections among blood donors in Tehran-Iran. Iran J Public Health 2014;43:981-9.

22. AL-Mosawy WF. Effect of transfusion interval rate on clinical manifestations of patients with beta-thalassemia major and their correlation with some biochemical parameters. Kerbala J Pharm Sci 2017; $13: 249-57$

23. Saha AK, Sahadalal BS. Frequency and distribution of blood groups in the donors of a rural hospitals, West Bengal, India. Int J Pharm Bio Sci 2016;7:B414-8

24. Iqbal M, Niazi A, Tahir M. Frequency of abo and rh blood groups in healthy donors. J Rawalpindi Med Coll 2009;13:92-4.

25. Soliman AT, El Banna N, Fattah MA, El Zalabani MM, Ansari BM. Bone mineral density in prepubertal children with beta-thalassemia: Correlation with growth and hormonal data. Metabolism 1998;47:541-8.

26. Mohseni F, Mohajeri-Tehrani MR, Larijani B, Hamidi Z. Relation between bmd and biochemical, transfusion and endocrinological parameters in pediatric thalassemic patients. Arch Osteoporos 2014;9:174.

27. Fuchs GJ, Tienboon P, Khaled MA, Nimsakul S, Linpisarn S, Faruque AS, et al. Nutritional support and growth in thalassaemia major. Arch Dis Child 1997;76:509-12.

28. Rosen CJ, Klibanski A. Bone, fat, and body composition: Evolving concepts in the pathogenesis of osteoporosis. Am J Med 2009; 122:409-14.

29. Fung EB, Xu Y, Kwiatkowski JL, Vogiatzi MG, Neufeld E, Olivieri N, et al. Relationship between chronic transfusion therapy and body composition in subjects with thalassemia. J Pediatr 2010;157:641-7, 647, e641-2.

30. Kattamis C, Liakopoulou T, Kattamis A. Growth and development in children with thalassaemia major. Acta Paediatr Scand Suppl 1990; 366:111-7.

31. Tienboon P, Sanguansermsri T, Fuchs GJ. Malnutrition and growth abnormalities in children with beta thalassemia major. Southeast Asian J Trop Med Public Health 1996;27:356-61

32. Filosa A, Di Maio S, Esposito G, De Martinis F, De Terlizzi F. Persistence of delayed adrenarche in boys with thalassemia. J Pediatr Endocrinol Metab 2001;14:407-14.

33. Asadi-Pooya AA, Karamifar H. Body mass index in children with betathalassemia major. Turk J Haematol 2004;21:177-80.

34. Allegra A, Capra M, Cuccia L, Pulejo ML, Raineri L, Corselli F, et al. Hypogonadism in beta-thalassemic adolescents: A characteristic pituitary-gonadal impairment. The ineffectiveness of long-term iron chelation therapy. Gynecol Endocrinol 1990;4:181-91.

35. Soliman AT, elZalabany MM, Ragab M, Fattah MA, Hassab H, Rogol $\mathrm{AD}$, et al. Spontaneous and gnrh-provoked gonadotropin secretion and testosterone response to human chorionic gonadotropin in adolescent boys with thalassaemia major and delayed puberty. J Trop Pediatr 2000;46:79-85.

36. De Sanctis V, Elawwa A, Angastiniotis M, Eleftheriou A, Kattamis C, Karimi M, et al. Highlights from the first thalassaemia forum on growth and endocrine complications in thalassemia doha, (october 2-3, 2011). Pediatr Endocrinol Rev 2012;9:672-9.

37. Wang C, Tso SC, Todd D. Hypogonadotropic hypogonadism in severe beta-thalassemia: Effect of chelation and pulsatile gonadotropinreleasing hormone therapy. J Clin Endocrinol Metab 1989;68:511-6.

38. Han X, Ren X, Zeng Y, Zhou Y, Song T, Cao X, et al. Physiological interactions between the hypothalamic-pituitary-gonadal axis and spleen in rams actively immunized against gnrh. Int Immunopharmacol 2016;38:275-83

39. Devarshi S, James S, Najafzadeh E, Pawar S, Kalrao V, Bafna V. Assessment of quality of life, complications and post-transfusion adverse reactions in thalassemia pediatric in tertiary care hospital. Int $\mathrm{J}$ Pharm Pharm Sci 2016;8:317-23

40. Tyagi P, Kumar Y, Gupta D, Singh H, Kumar A. Therapeutic advancements in management of iron overload- a review. Int J Pharm Pharm Sci 2015;7:35-44

41. Londan J, James VH, Wharton MJ. Threshold adrenocortical sensitivity in man and its possible application to corticotrophin bioassay. Lancer. 1967;2:697-700. 